\title{
Microfacies modeling method of seismic inversion constrained Cong Huang
}

\author{
No.5 Production Plant Of Daqing Oil Field
}

Keywords: seismic inversion; Sequential indicator; Reservoir modeling. The threshold value

\begin{abstract}
To enhance the interwell channel sand prediction accuracy of microfacies model, microfacies modeling based on sequential indicator stochastic approach is performed through integrated study and constrained by 3D seismic inversion and vertical fractional curve for sand body distribution and by using two-dimensional sedimentary facies as sand body boundaries constraints. The modeling results demonstrate that they not only reflect a trend of sand body distribution, but also improve the model prediction accuracy and reduce the uncertainty of the stochastic modeling.
\end{abstract}

\section{Introduction}

With the continuous development of seismic technology, its application gradually extends to different areas of oil and gas field development from oil and gas exploration. More and more studies integrated with geological and well logs have been widely applied to fine reservoir description. This dramatically enhances fluvial reservoir description accuracy. However, reservoir modeling seldom uses seismic data even though it usually uses sedimentary facies as a constraint of reservoir stochastic modeling. This type of model can reflect the reservoir geologic characteristics and the vertical heterogeneity of reservoir. But, it is difficult to predict reservoir lateral variation trend between wells. It also can't reflect the distribution of sand body to be consistent with seismic. This could easily lead to geological mis-understanding and to a poor oilfield development, especially in the small well spacing area. The geological model based on this method is more difficult to have a high accuracy. How to improve interwell channel sand body prediction accuracy in the model, truly reflect lateral change and vertical heterogeneity of the reservoir, has become a critical task of reservoir modeling.

Logs and seismic data are complementary in the reservoir prediction. Logs have high vertical resolution but poor lateral predictability, while seismic data has low vertical resolution but excellent lateral continuity. By integration of logs and seismic, both advantages can be applied to the modeling process. At present, facies constrained reservoir stochastic modeling and seismic inversion technique has been widely used in reservoir prediction with certain effectiveness. Microfacies modeling constrained by seismic inversion is a way to integrate both techniques. This method establishes reservoir microfacies model based on the sequential indicator modeling method and uses seismic inversion results as constraints. Therefore, it could capture not only the vertical reservoir heterogeneity but also the spatial distribution characteristics of sand body. It reduces the uncertainty of interwell sand body prediction.

\section{The principle of microfacies modeling inversion under the seismic inversion}

Constrained inversion microfacies modeling need the organic combination of inversion, Sedimentary facies characterization and geological modeling. The P-S wave velocity ratio inversion body used the method of geostatistics is used for constraint in the research.

Geostatistical inversion combinated geological knowledge, well logging and seismic data, in order to ensure the conform to the higher degree of inversion results and wells. The sedimentary facies belt graphs using seismic inversion section is used in this modeling. Using the seismic inversion results and the sedimentary facies belt graphs achievements together as the constraint to the microfacies modeling, can make the analoged space variables distributing along the trend predicted by the inversion, reproduce the geometry of space target and reduce the uncertainty of reservoir modeling. 


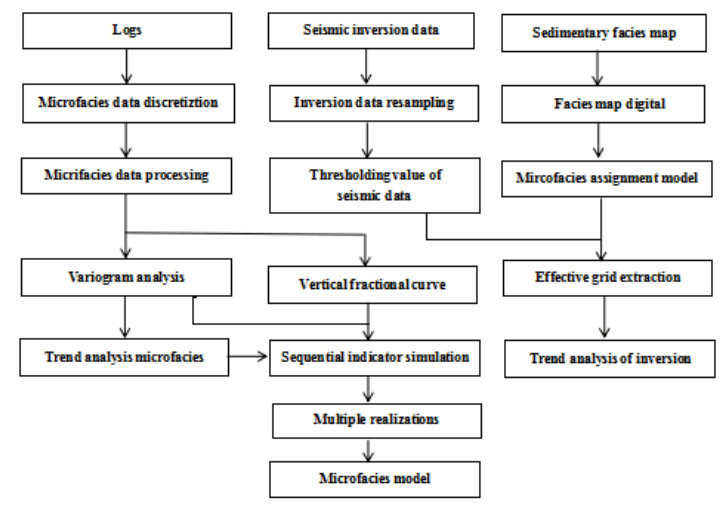

Figure 1 Inversion constrained microfacies modeling

flowchart

Reservoir modeling constrained by seismic inversion is mainly according to the following steps: 1. Establish the accuracy structure model based on the well data and seismic interpretation results. 2. Make accurate synthetic record, establish accurate velocity model and convert the inversion results to the depth of field. 3. Set up assignment microfacies model using sedimentary facies belt grap and sample the inversion body to the model grid. Then constraint inversion body to intercept river inversion data volume by using the assignment microfacies model. 4. Extract effective grids from the river inversion body using the method of threshold value, to establish inversion constraints. 5 . Analysis the sedimentary microfacies vertical proportion and the variation function. And using the inversion constraint body to constrait. Then establish an accurate mathematical model for microfacies reservoir microfacies model.

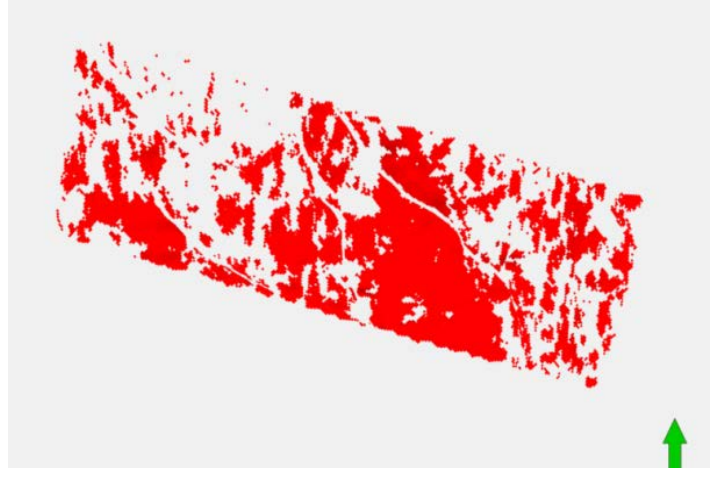

Figure 2 The sand body distribution of inversion constrained

The accurate structure model is the foundation of the reservoir modeling. In order to make the grid matching the sampling rate of earthquake, the accuracy of vertical construct should be less than 0.2 meters, to ensure that the after sampling inversion body is consistent with the original inversion body as far as possible. Seismic inversion can improve the accuracy and error can be introduced also. The purpose of the assignment model is to establish a framework of seismic constraint, then use the existing geological knowledge to effectively eliminate these sand body which are not match with the geological understanding because they are generated only using the inversion data volume constraint. 


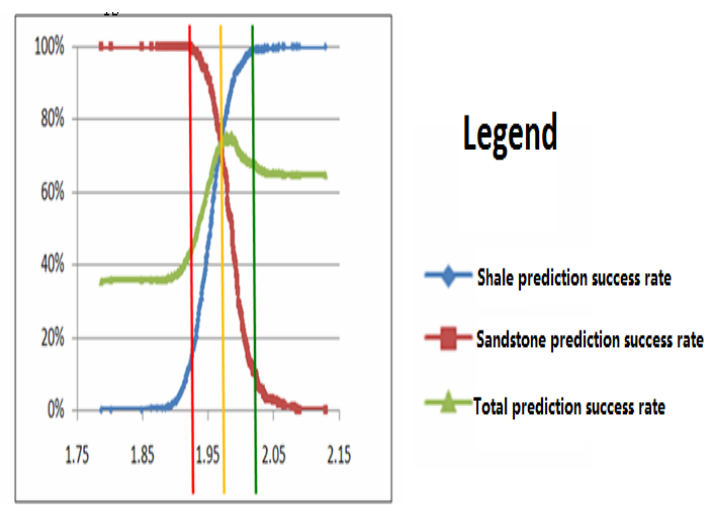

Figure 3 Inversion body and sand body coincidence rate

curve

The use of threshold value is the key of the inversion constrainted reservoir modeling. Find the threshold value between the inversion body and sand body using well seismic contrast, and set threshold value separately because different reservoir have different threshold value. Extract the reservoir inversion body according to the threshold value(Figure 3). The change trend of sand body internal reservoir is changed along with the development trend of the sand body forecasted by extracting inversion body. The research simulated inversion constraints using the Fecies-Model module of Petrel software, using inversion trend body received from the simulation as the constraint conditions of the reservoir modeling, sequential indicator simulation method as the foundation, and seismic inversion trend body as constraint.

\section{Application example analysis}

The research locates the southern of xingshugang oil field, a total of 10 faults. It's structure is simple, belongs to delta distributary plain facies, Material source is the northern provenance. Block has 498 wells, develops three reservoir groups. Purpose layer develops 3 sandstone groups, A single channel width is about 150 meters, The sand body thickness is more than 3 metres , effective thickness up to 7.2 meters.

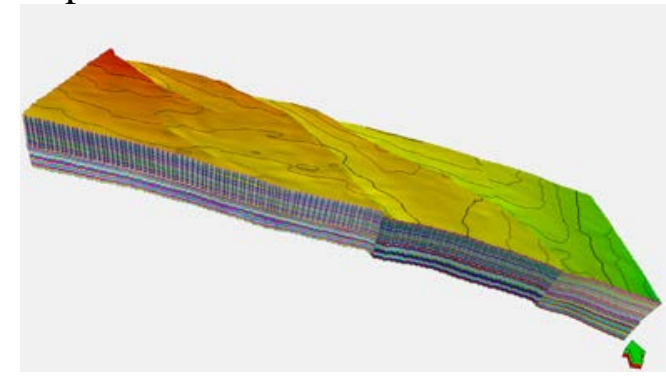

Figure 4 Structure model of the study area

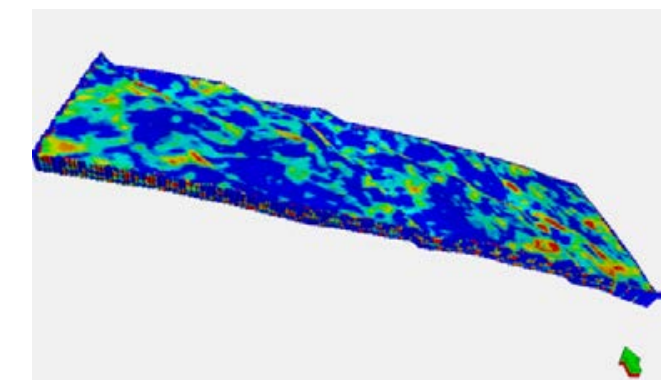

Figure 5 Resampling inversion body in the model

First, using well datas and results of seismic interpretation establish elaborate structure model. Planar grid uses 20 x 20 meters, vertical down to 0.1 meters. Using synthetic record establishes speed model, converts the time domain inversion body to depth domain. Using the seismic sampling tools in the geometric model, renew samples the inversion in depth domain to the model grid. We establish the assignment of sedimentary facies model that using assignment model intercepts inversion data volume within the river channel sand body, using the threshold value filters effective grids, making inversion of trend surface as the microfacies modeling constraints. We detailed analysis of variational function , make microfacies of scale function in vertical. Basing on the sequential indicator simulation method, using two-dimensional facies sand body boundary constraints planes, using three-dimensional inversion constraints the distribution of sand body, using vertical scale function constraints sand body vertical position, establishes reservoir microfacies model under the restriction of inversion. In order to better contrasting the effect of 
reservoir microfacies model under the constraint of inversion, we make microfacies model got from the algorithm of sequential indicator simulation only logging data involved..

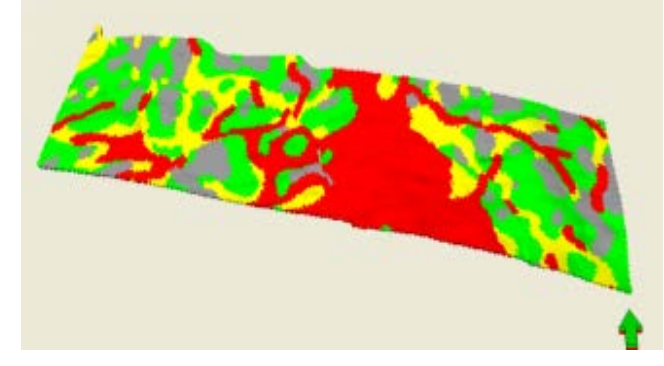

Figure 6 The sedimentary facies model of the assignment

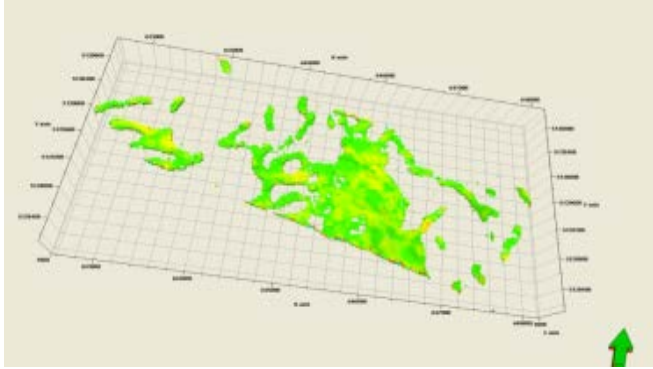

Figure 7 The trend model of seismic inversion

Comparing the model established by two methods, looking from the surface, sand body development in central area, Two kinds of method simulated the sand body contour is similar, But fewer sand body development in side, the shapes of sand body development are different , Reservoir microfacies model under the restriction of seismic inversion having a good continuity of sand body is obvious, Sand body morphology figure with facies, Modeling results close to the original understanding of geological characteristics, Sand body prediction precision is higher .

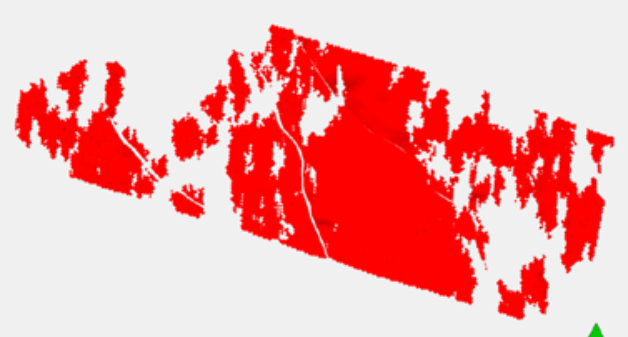

4

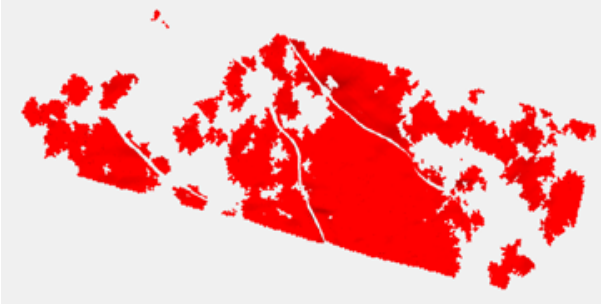

$A$

Figure 8 Reservoir microfacies model from Figure 9 Reservoir microfacies model from the well data inversion constraints

Choosing two Wells of inversion profile compared to model section, It can be seen that on the inversion profile interwell development has a good connecting relation between the channel sand body, In the model it develops channel sand body, and the changing trend of sand body is consistent with inversion prediction of trend, Characteristics of sand body distribution of no wellblock has higher prediction accuracy, This shows that reservoir modeling under the restriction of seismic inversion is a good way to control the uncertainty of interwell sand body prediction .

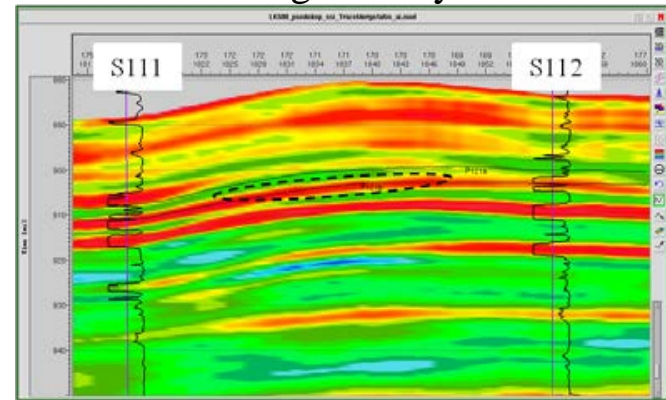

Figure 10 Seismic inversion profile

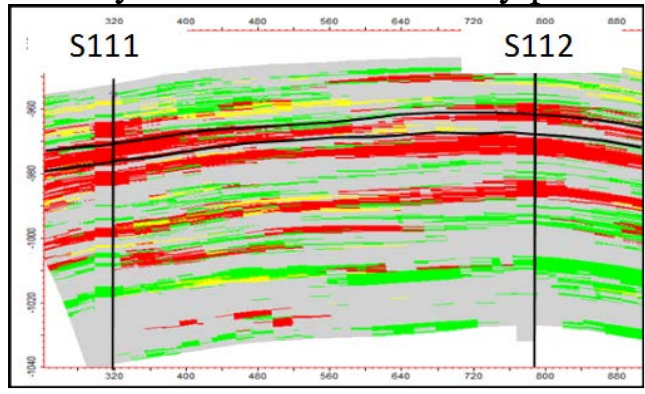

Figure 11 Model profile

\section{Conclusion}

(1) Reservoir microfacies modeling using the restriction of seismic inversion, can reduce the uncertainty of the distribution of interwell sand body in the process of reservoir modeling, and the simulation results more in line with geological knowledge;

(2) By studying , find a new method of reservoir modeling with well seismic combination , This method is based on the sequential indicator stochastic modeling theory, using two-dimensional sedimentary facies belt graph constrain sand body boundary, using three dimensional inversion 
body constrain the sand body distribution trend, using vertical ratio function constrain the longitudinal distribution of sand body .

\section{Reference}

[1] gong-yang Chen, Yong Hu yan-li zhou, etc. The methods of reservoir geologic modeling and practice under the restriction of seismic wave impedance [J]. Geological front, 2012, 19(2) : 67 73.

[2] wei liu, hong-qi liu, jian-ping li, etc. The instance of Petrel software application in reservoir geology modeling [J]. Journal of logging technology abroad, 2010, 30 (1) : 20-21.

[3] da-li weng, Qi-chao, Li-Jun Gao. Etc. The study of complex fault structure modeling in Nigeria 66 blocks [J]. Petroleum geology and engineering, 2012, 26 (1) : 38-43.

[4] Yong Hu, gong-yang Chen, yan-li zhou. The application of Seismic inversion data in phased reservoir modeling [J]. Oil and gas geophysical. 2011, 9 (2) : $11 \sim 43$.

[5] yong-gang zhang. Present situation and the development of seismic wave impedance inversion technique [J]. Journal of petroleum exploration, 2002, 9 (4) : $385 \sim 390$. 